\title{
Violência contra mulheres: interfaces com a Saúde
}

ensaios

\section{Lilia B. Schraiber ${ }^{1}$ \\ Ana Flávia Lucas Pires d'Oliveira ${ }^{2}$}

SCHRAIBER, L. B., D'OLIVEIRA, A. F. L. P. Violence against women: interfaces with Health care, Interface Comunicação, Saúde, Educação, v.3 , n.5, 1999.

This essay deals with the theme of violence from the standpoint of violence against women. It discusses the historical precedence of taking violence against women as a Legal issue and as an object of Justice, outlining parallels with the emergence of the problem as a Healthcare issue, as well as one of the targets of the Public Health area and of medical and sanitation practices.

KEY WORDS: violence, women's health; women's right; women.

Este ensaio procurará tratar do tema violência sob o recorte da violência contra mulheres. Discute a precedência histórica da tomada da violência contra a mulher como questão do Direito e objeto da Justiça, traçando paralelos na emergência do problema como questão de Saúde e alvo da Saúde Pública e das práticas médico-sanitárias.

PALAVRAS-CHAVE: violência; saúde da mulher; direito da mulher; mulheres.

${ }^{1}$ Professora da Faculdade de Medicina da USP/Departamento de Medicina Preventiva e docente/pesquisadora do Centro de Saúde Escola Samuel B. Pessoa. Email: liliabli@usp.br

${ }^{2}$ Médica sanitarista responsável pelo Programa de Saúde da Mulher no Centro de Saúde Escola Samuel B. Pessoa e doutoranda da Faculdade de Medicina da USP/ Departamento de Medicina Preventiva. 
Este ensaio procurará tratar do tema violência. Contudo, vamos fazê-lo sob um recorte especial: a violência contra mulheres. Uma das razões mais importantes para assim procedermos, em dias de crescentes denúncias das mais variadas formas de atos de violência no cotidiano social, é a de que se trata de uma experiência muito singular, singularidade esta que faz com que, mesmo nos dias atuais, em que, de fato, estamos nos voltando para a violência como grande problema social, a violência contra mulheres não encontre um adequado e profícuo canal de publicidade: não há, ainda, um lugar social e um campo de intervenção e saberes que a reconheça como objeto seu; como seu alvo de estudos, seu alvo de intervenção. Sem reconhecimento e definição de onde se alocar no espaço público, será difícil seu relato e exposição; será quase impossível um percurso de ação sobre ela. Por isso, muitos que a estudam apontam para sua invisibilidade social, com o que não apenas concordamos, mas, indo além, diríamos: não há onde ou como tornar-se plenamente visível. Não tem, exatamente, um "locus" seu nas práticas sociais, bem como não há linguagem apropriada para nomeá-la e lidar com suas questões internas - dos determinantes às suas conseqüências, no âmbito da vida e da saúde da mulher.

Dois têm sido seus campos recentes de algum acolhimento, nada por inteiro ou muito eficaz. No entanto, espaços e práticas sociais em que mulheres em situação de violência puderam e podem expressar de algum modo o problema e buscar algum tipo de intervenção. Em seqüência historiográfica, na década de 80 a Justiça e a partir dos anos 90 também a Saúde têm sido tais campos. Todavia, são, ambos, apenas "rotas imperfeitas".

Iniciando nossa discussão pelo termo mais geral - violência - diremos que este é um termo polissêmico e tem sido exaustivamente repetido pela mídia e trabalhado por inúmeros pensadores de áreas diversas. O termo, tal como usado, denota grande alargamento de nomeações, que vão desde as formas mais cruéis da tortura e do assassinato em massa, até aspectos mais sutis, mas considerados opressivos na vida moderna cotidiana, como a burocracia, a má distribuição de renda, certas normas culturais, entre outros.

Alguns pesquisadores que estudam a violência em geral propugnam definições abrangentes quanto ao contexto social, que levem em conta a chamada "violência estrutural" (Habermas, 1980; Joxe, 1981; Minayo, 1994; Bourdieu, 1995). Minayo (1994), definindo o campo de estudo da violência para a Saúde Pública, chama a atenção para a violência imperceptível, embutida na sociedade, determinada pela apropriação desigual de bens $e$ informações, que formaria uma rede menos aparente de violência, já que seriam "visíveis" apenas episódios mais agudos, como a violência física explícita. Para ela, a rede em seu todo é composta pela delinqüência, em seus aspectos rapidamente reconhecidos como violência, entre eles ferimentos, assassinatos e mortes; pela violência estrutural do Estado e das instituições que reproduzem as condições geradoras da violência; e pela resistência às condições de desigualdade, que algumas vezes se expressa também pela agressão física. Estas três formas articular-se-iam em rede $e$ estariam conectadas.

Domenach (1981) chama a atenção para o fato de a violência só recentemente ter se tornado um problema central para a humanidade, 
${ }^{3} \mathrm{O}$ autor considera que a violência é uma liberdade (real ou suposta) que se opõe e pretende submeter outras. E se é sempre moralmente condenável, por outro lado, é indissociável da experiência humana. Para ele, pois, condenar todas as violências é impossível e hipócrita. Fazer o elogio da violência, por outro lado, é criminoso. apesar de presente em toda a história. Conforme este autor, tornar certas práticas sociais uma questão de violência, associa-se à própria modernidade com seus valores de liberdade e felicidade, consolidados na criação da cidadania e dos direitos humanos para todos. A partir deste momento, ações que eram percebidas como inevitáveis na ordem do mundo e mesmo desejáveis passam a ser indesejáveis e combatidas. Criação humana, a violência, como as demais práticas sociais, pode e deve ser controlada, senão erradicada ${ }^{3}$.

Já a "violência contra a mulher" foi expressão cunhada pelo movimento social feminista há pouco mais de vinte anos. A expressão refere-se a situações tão diversas como a violência física, sexual e psicológica cometida por parceiros íntimos, o estupro, o abuso sexual de meninas, o assédio sexual no local de trabalho, a violência contra a homossexualidade, o tráfico de mulheres, o turismo sexual, a violência étnica e racial, a violência cometida pelo Estado, por ação ou omissão, a mutilação genital feminina, a violência $e$ os assassinatos ligados ao dote, o estupro em massa nas guerras e conflitos armados (Grossi, 1995; OEA, 1996).

Enunciada como prática da tradição nos relacionamentos amorosos em especial, a violência cometida por pessoas íntimas, que envolve também filhos, pais, sogros e outros parentes ou pessoas que vivam na mesma casa a que chamaríamos de violência doméstica - está profundamente arraigada na vida social, sendo percebida como situação normal. A noção de violência doméstica, algumas vezes associada apenas à violência conjugal contra a mulher, surge com força entre as feministas americanas e também do Brasil (Stark \& Flitcraft, 1996; Heise, 1994; Grossi, 1995; Saffioti, 1995), tornando pública e condenável uma situação antes corriqueira $e$ estritamente do domínio privado. Claro está que a noção de violência doméstica pode confundir-se com a idéia de violência intrafamiliar, neste caso modificando um pouco o espectro de agressores e agredidos (do domicílio para a família), bem como deslocando o olhar de gênero enquanto aproximação do problema. Do ponto de vista empírico, neste âmbito familiar de longe se destaca a magnitude dos atos contra as mulheres e meninas, mas o termo não deixa de ser referência para violência também contra meninos, homens, crianças ou idosos (em um recorte mais etário) e perpetrada por distintos familiares, em que se incluiriam igualmente as mulheres. Ao contrário do recorte "violência doméstica", a intrafamiliar é campo de estudo mais antigo, datando dos anos 70.

Mas no interior de todas essas concepções e termos usados para designar a violência contra mulheres, não há como negar a precedência da violência sexual, abrindo campo para evidenciar todas as demais. Neste caso, há outra mesclagem que se processa $e$ a violência pode ser perpetrada por conhecidos ou por estranhos, desde que referida às relações sexuais não consentidas e também referida a um aspecto relacional de difícil delimitação empírica, o assédio. No entanto, estes dois tipos quer de ato violento, quer de agressores, caracterizam situações distintas. A agressão sexual por um desconhecido é bastante diversa da mesma agressão cometida por uma pessoa próxima, íntima, que se ama (ou amou) e com quem se escolheu conviver, ainda que esta escolha seja algumas vezes mais próxima do

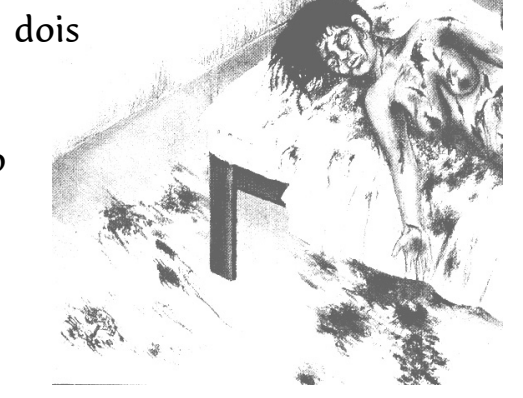

agosto, 1999 
constrangimento. E o assédio, tal qual a violência na esfera psicológica como muitos chamam as humilhações, ameaças ou desqualificações e, por vezes, as agressões a pessoas/bens queridos - são componentes da violência que dependem em muito dos contextos culturais das práticas amorosas ou dos relacionamentos entre homens e mulheres.

Esta conceituação, portanto, possui também interseções com as demais $e$ suas próprias imprecisões. O que vem sendo enunciado são formas diversas de violência, com expressões variadas e particulares, que compartilham este significado social comum - a iniqüidade de gênero (Heise, 1994).

A violência contra a mulher diz respeito, pois, a sofrimentos e agressões dirigidos especificamente às mulheres pelo fato de serem mulheres. Como termo genérico, agora para referir à situação experimentada pelas mulheres, quer remeter também a uma construção de gênero, isto é, se em primeiro lugar evidencia uma dada ocorrência sobre as mulheres, também quer significar a diferença de estatuto social da condição feminina, diferença esta que faz parecer certas situações de violência experimentadas pelas mulheres - especialmente a violência que se dá por agressores conhecidos, próximos e de relacionamento íntimo, como experiências de vida usuais.

A noção de gênero vem muitas vezes sendo confundida com a idéia de sexo feminino, quando em realidade surgiu exatamente para destacar essa distinção. Enquanto sexo indica uma diferença anatômica inscrita no corpo, gênero indica a construção social, material e simbólica, a partir desta diferença, que transforma bebês em homens e mulheres, em cada época $e$ lugar de distintas maneiras. A idéia é antiga. Simone de Beauvoir (1970) já dizia, desde os anos 50, que não se nasce mulher, torna-se mulher. O que tem um surpreendente avanço nos anos 80 e 90 é o refinamento e a complexificação desta idéia e uma ampliação de seu uso nos mais diversos campos de estudo, tais como História, Antropologia, Sociologia, Psicologia, Direito, Crítica literária, Psicanálise, Educação, Saúde e Economia, entre outros. Em um dos textos mais conhecidos que definem o conceito (Scott, 1995), gênero é essencialmente definido como uma interseção entre duas proposições: ... o gênero é um elemento constitutivo de relações sociais baseado nas diferenças percebidas entre os sexos, e o gênero é uma forma primeira de significar as relações de poder (p.14).

Masculino e o feminino são, pois, constructos sociais, o que se contrapõe à noção da essencialidade dos comportamentos sociais com base nas características sexuais: o homem sempre poderoso e agressor; a mulher sempre desprotegida e vítima...

Cabe, no entanto, ressaltar que a nomeação de "vítima" permaneçce muito associada à mulher até por razões históricas, fato relacionado às origens da tomada da violência contra mulheres como evento passível de intervenção na esfera pública. Iniciando-se a visibilização dessa situação vivida como um problema público e uma questão de Justiça, bem como iniciando-se alguma intervenção social de proteção às mulheres no campo dos Direitos Humanos, com o reconhecimento de atos violentos e dos assassinatos das mulheres (o que em passado não tão remoto foi aceito em nome da "defesa da honra" masculina), passa a Justiça legalmente a reconhecer familiares como "agressores"/ criminosos e mulheres, como "vítimas". Se o termo cabe com precisão na linguagem do Direito, é evidente a expansão semântica que se dá para seu uso disseminado em 
${ }^{4}$ É interessante registrar que recentemente o jornal "Folha de São Paulo" publicou uma série de depoimentos de escritores, homens e mulheres, em que revendo Dom

Casmurro de Machado de Assis,

pronunciavam-se todos acerca de CAPITU, julgando-a quanto à questão do suposto adultério, tema central da trama do romance. E o título-chamada da matéria foi CAPITU absolvida! Eis a boa mudança dos tempos.

${ }^{5}$ Claro está que há um grande movimento contemporâneo no sentido de começar a incluir os homens nos projetos de investigação e trabalho com o tema, mas os esforços ainda

são incipientes $e$

claramente

minoritários. outras esferas de atuação não pertencentes ao exercício da lei e julgamento dos crimes. No campo jurídico todas as pessoas em conflito, sejam homens ou mulheres, serão ou réus ou vítimas... Já nas esferas, por exemplo, da saúde, da assistência social ou outras formas de atuação, a tomada de qualquer sujeito na condição de "vitima" é significá-lo de saída como sujeito de "menor potencialidade" diante das suas possibilidades de vir a ser sujeito plenamente potente, isto é, de deter plenamente auto-domínio e soberania de decisões, daí que se perpetue a noção da mulher como um sujeito incapaz, à semelhança das crianças, dos doentes... ou dos loucos, em maior grau! Incapaz de decisões, incapaz de pleno domínio de si... então necessitaria de eternos "tutores"!

Ora, esta é a própria construção social do feminino denunciada $e$ repudiada pelo movimento de mulheres e que constrói a concepção das mulheres como eternos "dependentes". Pode, do ponto de vista histórico, explicar, sem eticamente justificar, tanto a cultura da "proteção" necessária (passando as próprias mulheres a se conceberem da mesma forma $e$ conceberem seus companheiros como "os provedores"), proteção que não se confunde com "cuidado", quanto a cultura de que os sujeitos dependentes, sempre infantilizados como sujeitos sociais, precisam de eterna vigilância $e$ educação rigorosa, o que em passado já bem próximo, significava punições físicas e sanções morais, para o aprendizado da adequada conduta social. Assim, não será espantoso que agressores e agredidas pensem a si próprios numa relação mais educativa que de casal, fazendo parte esta "educação" do sentimento amoroso! 4

Além disto, o advento, nos anos 90, do uso generalizado do conceito de gênero não deslocou inteiramente a abordagem e o direcionamento das ações implementadas de seu alvo preferencial - a mulher - para pensar também estratégias de conhecimento e intervenção sobre os homens ${ }^{5}$, pelas mesmas raízes históricas já apontadas.

Tais considerações foram feitas não com o intuito de se tratar, aqui, desta complexa questão. A vitimização das mulheres e o significado sóciocultural da problemática interativa, das relações intersubjetivas em geral $e$ no âmbito familiar e conjugal, em particular, constitui tema merecedor de tratamento mais profundo e detalhado. O que quisemos apontar, como se desenvolverá a seguir, foi, de um lado, a precedência histórica da tomada da violência contra mulheres como questão do Direito e objeto da Justiça, para à frente traçarmos paralelos com sua emergência como questão de Saúde (qualidade de vida) e alvo da Saúde Pública e das práticas médico-sanitárias. De outro lado, quisemos destacar o fato de que, sem linguagem própria, a violência contra mulheres vê-se revestida de "linguagens emprestadas", códigos, nomes, formas de expressar e formas de pensar que serão usadas de "empréstimo" pelas mulheres que querem se comunicar ou lidar com o problema no interior dessa situação vivida/relatada ou situação a ser compreendida/apreendida.

\section{Do direito à Saúde}

No Brasil, desde os primeiros anos da década de 80 , surge um ativo movimento feminista que tem duas principais bandeiras: a violência e a saúde da mulher. Nesta época, o assassinato de algumas mulheres de classe 
média por seus maridos ou ex-maridos é acompanhada de intensa mobilização para evitar a absolvição dos criminosos com base nos argumentos de "legítima defesa da honra" e caráter "passional" do crime, como era comum ocorrer então (Verardo, 1995). Acusando a impunidade reinante para os crimes de violência conjugal, e a transformação da vítima em ré através de seu julgamento moral, o movimento passa a solicitar a princípio que os crimes cometidos nas relações íntimas tivessem um tratamento equivalente aos crimes de igual natureza ocorridos entre desconhecidos, nas ruas, baseado no fato de que os direitos deveriam ser iguais para todos.

Enunciado o problema da violência conjugal, o que era uma situação comum mantida em segredo no mundo privado, passa a ganhar o espaço público e "exigir" soluções. A partir daí, várias iniciativas de apoio às mulheres são organizadas por grupos feministas em diversas cidades do país, como os SOS-Mulher em São Paulo, Rio de Janeiro e Porto Alegre. Estes serviços, mantidos voluntariamente por feministas, tiveram dificuldades e precariedades institucionais (Verardo, 1995), mas seu objetivo foi cumprido: a violencia contra a mulher, na sua forma mais conhecida, a violência conjugal, era agora uma questão pública.

O movimento de mulheres inicia parcerias com o Estado no sentido da implementação de políticas públicas para trabalhar com esse problema. Em 1983 é criado o Conselho Estadual da Condição

Feminina, em São Paulo; em 1985 é criado o Conselho Nacional dos Direitos da Mulher e a primeira Delegacia de Defesa da Mulher (DDM), também no Estado de São Paulo. A instituição das DDMs permitiu que delegacias especiais para crimes contra a mulher, com funcionárias exclusivamente mulheres e devidamente treinadas, fossem implantadas, dando enorme visibilidade ao problema. O Brasil foi o primeiro país no mundo a propor este tipo de intervenção. Hoje em dia, já são mais de cem DDMs só no Estado de São Paulo, mais de 180 em todo o país (Brandão, 1996) e inúmeras delegacias do mesmo tipo em diversos países da América Latina (Red de Salud de las Mujeres Latinoamericanas y del Caribe, 1996).

As DDMs foram o primeiro e grande recurso no combate público à violência contra a mulher e especialmente à violência conjugal no país. Seu caráter é basicamente policial: detectar transgressões à lei, averiguar sua procedência e criminalizar a violência doméstica.

Note-se que quando é enunciada como desvio da normatividade social, e não mais uma norma aceita socialmente, a violência doméstica foi interpretada em primeiro lugar como um crime, e que, apesar da saúde ser uma importante bandeira feminista, durante a década de 80 , a idéia desta forma de violência como um problema da esfera da saúde era quase inexistente. O crime é uma transgressão da norma social aceita, e, como tal, enquadra-se na lei e é passível de responsabilização e punição. 
No entanto, ainda que a lei a princípio seja feita para ser aplicada a todas as relações interpessoais, observam-se muitas dificuldades ao tentar aplicá-la na esfera das relações conjugais, familiares e muito íntimas. O crime de lesão corporal leve, por exemplo, tem características e sentidos muito diversos quando se trata da briga de dois desconhecidos em um bar ou das relações cotidianas de um casal, mas a lei brasileira não considera este fato na definição e apuração do crime e na determinação da pena. Esta diversidade não significa que um crime seja mais legítimo que o outro, mas sim que assumem significados diversos para os presentes.

Dirigir a questão da violência doméstica ao Judiciário acabou por tornar aparente que os crimes cometidos por pessoas muito próximas das vítimas têm uma configuração própria e necessitam regulação penal e também civil específicas, além de um compromisso do Estado em garantir o acesso e o funcionamento desses mecanismos. Também deixa claro que as leis podem encobrir a desigualdade justamente pelo apelo da igualdade. Nem todos são iguais perante a lei, embora para a lei todos sejam exatamente iguais, como sabemos.

Diversos países latino-americanos aprovaram, nos últimos anos, leis específicas para a violência doméstica (Red de Salud de las Mujeres Latinoamericanas y del Caribe, 1996), mas o Brasil ainda não realizou este passo. As avaliações desses processos demonstram, entretanto, que, mesmo com leis específicas para a violência doméstica, a linguagem jurídica continua apresentando muitos problemas para enquadrar as situações de violência.

A partir dos anos 90, além de remeter o problema à área da justiça e da polícia, que demonstraram resistências importantes e diversos problemas na incorporação do tema, o movimento de mulheres inicia nova estratégia. A discussão da violência contra a mulher foi remetida estratégica $e$ conscientemente para três campos principais: os direitos humanos, a saúde e o desenvolvimento social, os três já consolidados e reconhecidos internacionalmente (Heise et al., 1996). O movimento buscou associar a violência a estas questões já reconhecidas como importantes, utilizando este prestígio para colocar a violência contra a mulher na agenda internacional. Além disto, estes campos tinham conceitos e ferramentas que poderiam ser úteis no trabalho com a violência contra a mulher, tais como a linguagem dos direitos e a noção de prevenção, por exemplo.

Ao fazer este movimento, o tema encontra novas linguagens possíveis de expressão e trabalho além da jurídica e policial, e passa a ser explorado como um problema também de saúde.

Os dados epidemiológicos são bastante expressivos. Os homens, e especialmente os homens jovens, estariam muito mais sujeitos que as mulheres à violência no espaço público, e especialmente ao homicídio, cometido por estranhos ou conhecidos. Já as mulheres estão mais sujeitas a serem agredidas por pessoas conhecidas e íntimas do que por desconhecidos, o que pode significar violência repetida e continuada que, muitas vezes, se perpetua cronicamente por muitos anos ou até vidas inteiras.

As estatísticas a seguir dão uma noção da prevalência disseminada do problema ao redor do mundo, e especialmente em alguns países do continente americano, ainda que de forma grosseira e com diferenças importantes na metodologia de coleta de dados: 


\begin{tabular}{|c|c|c|c|}
\hline País e autor & Amostra & Tipo de amostra & Achados \\
\hline $\begin{array}{c}\text { Canadá } \\
\text { (Statistics Canada, } \\
\text { 1993) }\end{array}$ & $\begin{array}{l}12300 \text { mulheres de } \\
18 \text { anos ou mais }\end{array}$ & $\begin{array}{l}\text { Amostra nacional } \\
\text { representativa }\end{array}$ & $\begin{array}{c}25 \% \text { das mulheres ( } 29 \% \text { das } \\
\text { que alguma vez foram } \\
\text { casadas) informam haver sido } \\
\text { atacadas fisicamente por } \\
\text { companheiro atual ou } \\
\text { anterior desde os } 16 \text { anos de } \\
\text { idade. }\end{array}$ \\
\hline $\begin{array}{l}\text { Chile } \\
\text { (Larrain, 1993) }\end{array}$ & $\begin{array}{l}1000 \text { mulheres } \\
\text { entre } 22 \text { e } 55 \text { anos } \\
\text { em Santiago } \\
\text { envolvidas em uma } \\
\text { relação por } 2 \text { ou } \\
\text { mais anos }\end{array}$ & $\begin{array}{l}\text { Amostra aleatória } \\
\text { estratificada }\end{array}$ & $\begin{array}{l}60 \% \text { foram abusadas por } \\
\text { companheiro, } 26,2 \% \text { foram } \\
\text { fisicamente abusadas }\end{array}$ \\
\hline Colômbia, 1990 & $\begin{array}{l}3272 \text { mulheres } \\
\text { urbanas; } 2118 \\
\text { mulheres rurais }\end{array}$ & $\begin{array}{l}\text { Amostra nacional } \\
\text { representativa }\end{array}$ & $\begin{array}{c}20 \% \text { abusadas fisicamente, } 33 \% \\
\text { abusadas psicologicamente, } \\
10 \% \text { estupradas pelo marido }\end{array}$ \\
\hline $\begin{array}{c}\text { Nicarágua, Leon } \\
\text { (Ellsberg et al., 1998) }\end{array}$ & $\begin{array}{c}488 \text { mulheres de } 15 \\
\text { a } 49 \text { anos }\end{array}$ & $\begin{array}{l}\text { Amostra } \\
\text { representativa }\end{array}$ & $52 \%$ de violência física \\
\hline EUA, 1986 & $\begin{array}{l}2143 \text { casais } \\
\text { oficialmente } \\
\text { casados ou } \\
\text { coabitando }\end{array}$ & $\begin{array}{c}\text { Amostra } \\
\text { probabilística a nível } \\
\text { nacional }\end{array}$ & $\begin{array}{l}28 \% \text { reportam ao menos um } \\
\text { episódio de violência física }\end{array}$ \\
\hline
\end{tabular}

Adaptado de Heise et al., 1994

Esta violência tem conseqüências para a saúde que vão além dos traumas óbvios das agressões físicas. A violência conjugal tem sido associada com o aumento de diversos problemas de saúde como baixo peso ao nascer, queixas ginecológicas, depressão, suicídio (Stark \& Flitcraft, 1996), gravidez indesejada e doenças sexualmente transmissíveis (DST), queixas gastrointestinais, queixas vagas, e outras (Heise et al., 1994).

A prevalência de violência na gestação tende a ser ainda maior que os índices de prevalência encontrados para violência física e sexual no último ano em populações não grávidas. Isto fez com que alguns autores postulassem que a gravidez poderia consistir um risco aumentado para violência (Stark \& Flitcraft, 1991; McFarlane, 1992).

Mulheres que sofrem violência física e sexual parecem utilizar mais os serviços de saúde. Por outro lado, os profissionais de saúde não identificam ou pelo menos não registram a violência em prontuário como parte do atendimento. Stark \& Flitcraft (1996) encontraram 2,8\% de casos de violência doméstica identificados pelos médicos em uma consulta em serviço de emergência, enquanto o estudo mais detalhado de todo o prontuário mostrou que 9,6\% destas mulheres tinham sido agredidas físicamente $e$ 15,4\% delas tinham histórias de lesões prováveis ou sugestivas de violência doméstica. Em São Paulo, estudo em um serviço de atenção primária mostrou que $57 \%$ das mulheres atendidas relataram algum episódio de violência física na vida. Apenas $10 \%$ dos casos estavam registrados em prontuário (Schraiber \& D'Oliveira, 1999).

Embora muitas vezes não registrem nenhuma menção à violência 
doméstica, os profissionais de alguma forma reconhecem a situação, porque prescrevem diferenciadamente: $24 \%$ das mulheres em situação de violência atendidas em um pronto-socorro receberam tranquilizantes ou analgésicos, enquanto $9 \%$ das mulheres com lesões não intencionais tinham a mesma prescrição. Quando reconhecida, ainda que não registrada como tal, a situação de violência também leva a mais encaminhamentos para serviços de saúde mental: $15 \%$ das pacientes que viviam situações de violência doméstica tiveram este tipo de encaminhamento, enquanto apenas $4 \%$ das vítimas de lesões não intencionais receberam a mesma orientação (Stark \& Flitcraft, 1996).

Um estudo que tem sido muito citado (Sugg, 1992) busca estudar as barreiras à esta detecção pelos profissionais médicos. Foram realizadas entrevistas abertas com 38 profissionais, predominantemente médicos de atenção primária de uma rede de serviços da $\mathrm{HMO}$ em Washington, buscando as dificuldades percebidas por esses profissionais para a identificação do tema. Os autores utilizam no título uma associação bastante expressiva: trabalhar com a violência é difícil porque é como abrir a Caixa de Pandora. Este mito foi citado repetidamente pelos entrevistados e refere-se a uma caixa que, assim que aberta, libera a doença, a insanidade, o vício, a maldade no mundo. Este mito mostra o medo de trabalhar com "diabos" que poderiam ser liberados ao se tratar do assunto (Sugg \& Inui, 1992).

As propostas para a área de saúde têm sido, basicamente, as de introduzir a busca ativa de casos, com perguntas rotineiras nas anamneses de serviços de diversas naturezas (Pronto-socorro, pré-natal, ginecologia, saúde mental etc...) para a identificação, registro e referência adequada dos casos.

No Brasil, temos uma outra intersecção interessante, que diz respeito à introdução, no inicio dos anos 90, da realização do aborto legal (estupro e risco de vida para a mãe) na rede pública de saúde. Este movimento resultou em mais de dez hospitais em todo o país que hoje realizam o procedimento, alguns dos quais também prestam assistência multidisciplinar às vítimas de violência sexual. Mas a incorporação da violência à área de saúde não se dá sem questões. Assim como a linguagem do crime não expressa adequadamente toda a complexidade da violência doméstica e sexual, tampouco a linguagem da doença consegue este feito, guardando possibilidades, mas também riscos importantes.

\section{Delegacias de Defesa da Mulher e Serviços de Saúde}

Apesar das DDMs, e do aumento de denúncias que elas propiciaram, a impunidade continua e muitos processos não são instaurados, poucos chegam a julgamento e o número de condenados é ínfimo. Esta ineficácia das DDMs deve ser analisada com cuidado, porque pode iluminar alguns aspectos importantes para pensarmos a incorporação do tema pela Saúde. A retirada da queixa, procedimento muito comum, podendo atingir cerca de $70 \%$ dos registros (Brandão, 1996), é um fato recorrente que vem minando a credibilidade da estratégia, já que reforça o mito de que as mulheres não "querem" mudar a sua situação, e "gostam de apanhar". É interessante notar, entretanto, que o uso das DDMs pelas mulheres parece seguir uma 
lógica diversa da lógica da instituição policial, e mesmo do movimento feminista, como nos mostra Brandão.

Se para a polícia a queixa tem que ser tratada do ponto de vista penal, isto é, na linguagem jurídica do crime, as mulheres que se queixam raramente consideram essas queixas como passíveis de criminalização. Tendo as Delegacias como único recurso visível de enfrentamento do problema, bastante legitimado entre as classes populares e extremamente divulgado nos últimos anos, especialmente pelo movimento feminista, como um lugar de defesa dos direitos da mulher, as mulheres buscam nelas uma mediação do conflito privado. A concepção do que seja exatamente "direitos" ou "interesses" das mulheres, entretanto, varia bastante, e uma boa parte da demanda dirigida às Delegacias são intervenções na área civil, como soluções legais para a separação ou outras expectativas, tais como "dar uma dura" no marido, que não se enquadram na função primária da polícia penal tal como compreendido pelas trabalhadoras das Delegacias, isto é, verificar e apurar o crime. As mulheres que procuram a DDM têm uma visão global de seu problema, cujo sentido é bem mais complexo do que os crimes tipificados em lei, como a lesão corporal. A própria agressão física pode não ser o problema para algumas delas, já que a perturbação da ordem familiar que ela indica pode ser bem mais importante. Brandão nota, entretanto, que assim que as mulheres pesquisadas percebem que sua "queixa" não pode ser reconhecida pela instituição policial, tratam de tentar adequar sua demanda à linguagem jurídica do crime, denunciando, por exemplo, uma "ameaça", para legitimar a reclamação de um marido que está perturbando a ordem doméstica, por exemplo, com amantes e bebedeiras, já que o problema assim enunciado não se enquadra em nenhum crime previsto em lei.

Por outro lado, as trabalhadoras das DDMs tampouco consideram as queixas como pertencentes ao que entendem como seu campo de atuação, já que muitas vezes estas não podem ser enquadradas em crimes tipificados em lei, e já que percebem que a intenção das mulheres muitas vezes está distante da idéia de punir seus parceiros conforme previsto em lei. A retirada da queixa é um procedimento extremamente comum que resulta da interação das "vítimas", hesitantes em criminalizar penalmente o parceiro que está perturbando a ordem doméstica, com as policiais, que percebem nas queixas uma situação mais "social" ou "psicológica", desqualificando-as como crime. Nesse sentido, as profissionais da Delegacia e as mulheres que as demandam compartilham de igual interpretação do fato: a violência doméstica não lhes parece uma ocorrência passível de criminalização. Daí o encontro que se verifica no ato de retirada da queixa.

Este encontro contrasta fortemente com a proposta de política pública reivindicada pelo movimento feminista, assumida pelo Estado e materializada nas DDMs, que busca justamente tratar esses eventos como crimes passíveis de averiguação e punição, baseando-se em uma idéia liberal de direitos individuais. Brandão (1996) ressalta que esta interpretação da retirada da queixa lhe dá um sentido diverso da idéia comum de que o procedimento seria fruto da "falta de consciência" das mulheres de seus direitos ou de sua cidadania, ou de sua submissão, enquadrando o processo como uma ocorrência institucional a partir de concepções de direitos diversas. 
A retirada da queixa não é, entretanto, percebida pelas mulheres como contraditória ao movimento que as levou a registrá-la. Ao contrário, elas tendem a retomar a negociação com o acusado em uma posição superior à qual se encontravam anteriormente. Na ótica dessas mulheres, a suspensão do processo seria, então, não um ato contraditório à denúncia, mas um elemento que pode favorecer o retorno da reciprocidade rompida, que é muitas vezes o seu interesse principal (Brandão, 1996). Por outro lado, para as trabalhadoras das Delegacias, a retirada da queixa confirma a idéia de que a demanda foi mal dirigida, não estando dentro de sua competência profissional de intervenção. Ainda que compartilhem da idéia de que as situações relatadas não se enquadrem como crime, usuárias e trabalhadoras divergem, portanto, quanto às expectativas de intervenção possível das Delegacias e aos resultados alcançados.

Podemos imaginar que com os serviços de saúde possa ocorrer situação análoga, guardadas as devidas especificidades. Além de transgressão da norma civil - crime -, a violência estará sendo, neste caso, nomeada como causadora de alterações da normatividade vital - doença.

Se para os policiais não é exatamente uma demanda pela ação penal diante de um possível crime, este sofrimento da mulher em situação de violência tampouco é doença para os médicos e profissionais de enfermagem, a não ser que haja alguma base anatomo-patológica objetiva para justificá-lo. Neste último caso, a interpretação de doença pode ser acolhida $e$ a violência perde seu sentido e sua importância, tendendo a ser desconsiderada. Do contrário, esta queixa é desqualificada, alegando-se ser de ordem social ou psicológica, e não é acolhida pelo serviço, que opera sob a racionalidade biomédica de intervenção, isto é, a doença como alteração anatomo-patológica enquanto alvo da atuação profissional.

Por outro lado, da perspectiva das mulheres, todo o sofrimento que levam aos serviços de saúde é potencialmente doença, e como tal pode e deve ser diagnosticado e tratado com base em um saber científico e, portanto, bastante legitimado. Esta nos parece ser a expectativa das mulheres em serviços de saúde em razão de sua própria constituição como usuárias.

Como se dá, então, a interação entre usuárias e profissionais de saúde, desde o momento em que a mulher percebe o sofrimento como doença $e$ resolve procurar um serviço, até o momento em que segue uma orientação $e$ tem (ou não) sua demanda atendida? $\mathrm{O}$ interior deste processo, a atividade assistencial em saúde, é o centro desta interação: é ali que é negociado (ou não) o quanto o sofrimento pode ser traduzido em doença, e os significados que isto pode ter nesta interação. É ali, portanto, que o que foi vivido pode ser percebido como transgressão e violência, ou não, e que as alternativas terapêuticas são negociadas ou impostas..

A área da saúde, assim como a polícia, tem dificuldades em trabalhar questões percebidas como culturais, ou sociais e até psicológicas. A proposta mais divulgada para os serviços, de simplesmente detectar a violência contra a mulher com busca ativa, de rotina, ou screening, pode ter o efeito inesperado de, detectada a violência, a demanda ser rejeitada como "nãodoença", porque social, ou por outro lado ser percebida como patologia, o que também levanta questões, por reduzir ao corpo individual aquilo que é por definição das interações humanas. A patologia não é responsabilidade 
daquele que está doente, e cabe ao profissional habilitado conduzir o doente de volta ao estado de normalidade. Para isto, o sujeito doente é expropriado de seu juízo privado acerca de seu corpo e deve entregar-se em mãos profissionais e seguir corretamente todas as prescrições. Parece-nos que, ao aplicar a idéia de doença à violência, podemos incorrer em um acirramento da idéia de vítimização colocada no início deste ensaio, reforçando a idéia de que as mulheres nessas situações seriam sujeitos incompletos, que necessitariam de uma tutela especializada. A solução pode acabar, assim, por ter um impacto menor sobre o problema ou muito diverso do esperado, como parece estar ocorrendo com as DDMs.

Existirá algum espaço próprio para este sofrimento que a princípio não "tem lugar"? Não tem lugar no corpo, não tem lugar no trabalho... Não tem lugar na lei, não tem lugar na patologia...

Terá este sofrimento sem lugar alguma linguagem que o represente? Como poderá ser expresso, falado, escrito, mostrado? Poderá ser escutado e compreendido no direito ou na saúde? Poderá ser trabalhado? De que forma? Quais suas conseqüências técnicas e políticas?

Sem lugar definido ou reconhecido no âmbito das práticas que poderiam acolher demandas e necessidades relacionadas à violência de gênero, a violência experimentada pelas mulheres e seus efeitos na vida e na saúde não encontram canais de expressão ou comunicação já que não possuem códigos, nomeações ou linguagens que lhe seriam próprias. Este vivido não é, por parte dos profissionais, reconhecido e nomeado como demanda a ser acolhida pelos dois discursos competentes aqui tratados: o da Lei e o da Medicina. O movimento de mulheres vem tratando de infiltrar nestes discursos uma linguagem própria para abordar a violência contra a mulher. Apesar de seus esforços e grandes avanços, no entanto, a Medicina e o Direito permanecem virtualmente impermeáveis em termos de uma linguagem própria de expressão do problema. Serão, entretanto, a nosso ver, alvo por parte das mulheres de uma tentativa de aproximação neste sentido: sem ser crime, a violência será uma espécie de "transgressão da ordem"; sem ser doença, uma espécie de "transgressão do corpo".

\section{Possibilidades de atuação na Saúde}

Nossos cinco anos de trabalho com a questão, associados à nossa experiência em implantação, supervisão e avaliação de Programas de Saúde de Atenção Primária e elaboração de um Guia Prático de Serviços (1999) nos permitem esboçar algumas opiniões preliminares de caminhos possíveis para que as rotas tentadas se tornem ao menos um pouco mais adequadas à expressão, ao acolhimento e à resposta para um problema tão comum e ao mesmo tempo tão ignorado no cotidiano das práticas em saúde.

A violência é uma situação de vida de difícil manejo e solução e está presente na vida da maioria das pessoas, em graus maiores ou menores. Por esta razão, devemos lembrar que os profissionais de saúde, assim como as policiais, não se encontram protegidos desta situação, e que muitas vezes, ao introduzir a questão em algum serviço para que se comece a trabalhá-la, necessitaremos acolher também os próprios profissionais; e que durante todo o trabalho deve-se ter atenção para esta questão (D'Oliveira \& Schraiber, 1998). Ao mobilizar para o problema, podemos tocar em 
situações latentes que podem agudizar-se na vida das(os) próprias(os) trabalhadoras(es) e de sua família, que devem receber supervisão e suporte.

Para que se possa abordar o problema nos serviços, é necessário contar com um espaço de expressão para as angústias e questões da clientela, que não se resuma à aproximação biomédica estrita, ou à busca de patologias conforme definidas pelo saber médico. Outros profissionais que atuam na saúde, como os de Psicologia, Enfermagem e Serviço Social, têm alguma experiência com a escuta de problemas que não são exclusivamente biomédicos. Isto não significa, obviamente, abandonar a vocação específica dos serviços, mas sim, em nome de sua melhor eficácia técnica, escutar a(o) usuária(o) em toda a complexidade de sua demanda. Já está demonstrado o quanto a violência pode estar relacionada a diversos problemas de saúde comuns na prática clínica e à baixa resolutividade do serviço em suas ações. Ouvir a demanda relacionada à violência significa ouvir o usuário (e isto é bastante complexo!!), e também a estar consciente da existência do problema e poder perguntar sobre ele, no momento apropriado e sem constrangimentos. Uma situação que afeta de 20 a $50 \%$ das mulheres não pode ser objeto de estigmatização ou vergonha $e$ o receio dos profissionais em abordar o assunto muitas vezes expressa um julgamento moral próprio, e não um constrangimento em expor a situação por parte das usuárias. Portanto, é necessário pensarmos, em cada serviço e em cada situação assistencial, quais seriam os canais de expressão, grupais ou individuais, mais propícios e adequados para possibilitar a emergência da questão.

É necessário que a situação enunciada seja acolhida, qualificada e tratada com respeito e sigilo estrito. O grande risco aqui é tratarmos a violência como uma doença ou como um risco em saúde, e deduzirmos imediatamente daí um conjunto de procedimentos e ações que a mulher deve seguir para poder "curar-se" do problema. Se a violência é um problema com sérias conseqüências para a saúde, ela é uma situação que extrapola em muito esta esfera, e continua sendo uma situação de vida, com toda a complexidade que isto implica. A pressa dos profissionais de saúde em tratar o problema pode ser extremamente contraproducente, uma outra violência, já que pode desrespeitar a trajetória da mulher e da família, e acabará por frustrar os trabalhadores que se sentirão pouco "resolutivos" em sanar o problema. Qualificar a violência como algo indesejável e injusto pode reforçar a situação para a pessoa, já que legitima seu sofrimento; por outro lado, abre possibilidades de transformação pela consciência do processo a que se submete.

A resolução do problema, quando possível, não se dará no âmbito específico da saúde. Portanto, é necessário que os serviços de saúde, ao abordarem o problema, estabeleçam com cada mulher uma escuta responsável, exponham as alternativas disponíveis em termos de acolhimento e intervenção (DDM, apoio jurídico, apoio psicológico, casa abrigo, ONGs etc...) e decidam com ela qual seriam as alternativas melhores para o caso, incluindo-a ativamente na responsabilidade pelo destino de sua vida.

No município de São Paulo, reunimos informações sobre todas as opções assistenciais existentes, compilamos essas informações separando-as por diversas modalidades

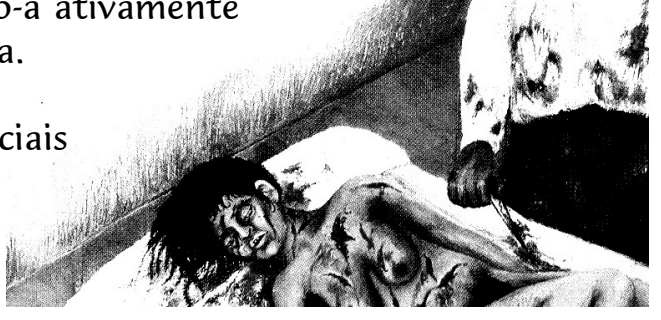


assistenciais (policial, jurídica, psicossocial especializada e básica e médica) e publicamos um Guia de Serviços contendo todo este material. O Guia vem sendo distribuído para todos os serviços que prestam assistência a mulheres na cidade, e constitui material fundamental para este trabalho, disponibilizando as referências possíveis. A decisão compartilhada é fundamental aqui, para que consideremos a mulher como um sujeito pleno, e não a violentemos mais uma vez ao tratá-la como incapaz. $O$ encaminhamento decidido de forma unilateral pelo profissional de saúde, e algumas vezes mal compreendido pela mulher, pode ter resultados desastrosos, como é o caso da referência quase automática para serviços psicológicos, que podem ser interpretados pela mulher (e algumas vezes por sua família) como um atestado de que o problema é exclusivamente seu e que seu funcionamento subjetivo estaria alterado de alguma forma (doença da cabeça). Além disto, é necessário respeitar o tempo de cada uma. Muitas vezes a conversa ou informação que acontece hoje fará sentido ou será utilizada pela usuária meses, ou anos depois, a depender do seu processo e das suas condições objetivas. Isto não desmerece o trabalho, desde que não usemos critérios de resolutividade imediata para avaliá-lo, e sim a idéia de que a disseminação dessas informações para a população é importante na construção da idéia de cidadania. O simples conhecimento da existência de serviços especializados no assunto pode ter uma importância fundamental na percepção que a mulher tem do caráter social de sua situação, como demonstra nossa experiência.

É importante notar que, ao contrário do que parece ao senso comum, uma boa parte das pessoas que vivem em situações de violência já tiveram diversas decisões e ações no sentido de romper a violência, mas muitas vezes não foram bem sucedidas nas instituições às quais recorreram. Este caminho truncado de busca de alternativas foi nomeado como rota crítica por pesquisadores da Organização Panamericana de Saúde, e está repleto de desencontros, desestímulos e falta de acesso na tentativa de uso de Delegacias, advogados e outras instituições. Estando na rota da maioria das mulheres, que por um motivo ou outro o utilizam, os serviços de saúde têm o dever de constituir-se como um local de acolhimento e elaboração de projetos de apoio, ao invés de ser mais um obstáculo na tentativa empreendida pelas mulheres de transformação de sua situação.

\section{Referências bibliográficas}

BEAUVOIR, S. O segundo sexo. São Paulo: Difusão Européia do Livro, 1970.

BOURDIEU, P. A dominação masculina. Educ. Real., v.20, n.2, p.133-84, 1995.

BRANDÃO, E.R. Nos corredores de uma Delegacia da Mulher: um estudo etnográfico sobre as mulheres e a violência conjugal. Rio de Janeiro, 1996. Dissertação (Mestrado) - Instituto de Medicina Social, UERJ.

DOMENACH, J.M. La violencia. In: LA VIOLENCIA y sus causas. Paris: UNESCO, 1981.

D'OLIVEIRA, A.F.L.P., SCHRAIBER, L.B. Violence against women: a physician's concern? In: FIGO, XV World Congress of Gynecology and Obstetrics, 1998, Londres. Proceedings... Londres, 1998, p. 157-63. 
VIOLÊNCIA CONTRA MULHERES: INTERFACES...

ELLSBERG, M. et al. Confites en el infierno - prevalencia y caracteristicas de la violencia conyugal hacia las mujeres en Nicaragua. Managua, Leon: Red Nacional de mujeres contra la violencia, Departamento de Medicina Preventiva y Salud Publica, UNAN, Departamento de Epidemiologia y Salud Publica, Umea University, 1998.

GUIA Prático de Serviços. Município de São Paulo. Mulheres em situação de violência. 1999. 2.ed., Faculdade de Medicina da USP, Depto. de Medicina Preventiva; CSE Samuel B. Pessoa e Coletivo Feminista Sexualidade e Saúde. Apoio Fundação FORD, São Paulo. (1.ed., 1996).

GROSSI, M. O significado da violência nas relações de gênero no Brasil. Sexualid., Gênero e Saúde. v.2, n.4, 1995.

HABERMAS, J. O conceito de poder de Hannah Arendt. In: FREITAG, B.; ROUANET, S. P. (Orgs). Habermas. São Paulo: Ática, 1980. p.100-18. (Coleção Grandes Cientistas Sociais, v.15)

HEISE, L. et al. Violence against women. The hidden health burden. Washington: The international Bank for Reconstruction and Development, The World Bank, 1994.

JOXE, A. Introducción general. In: LA VIOLENCIA y sus causas. Paris: UNESCO, 1981.

MCFARLANE, J. et al. Assessing for abuse during pregnancy: severity and frequency of injuries and associated entry into prenatal care. JAMA, v.267, n.23, p.3176-8, 1992.

MINAYO, M. C. A violência social sob a perspectiva da Saúde Pública. Cad. Saúde Pública, v.10, supl.1, p.07-18, 1994.

OEA. Convenção interamericana para prevenir, punir e erradicar a violência contra a mulher: Convenção de Belém do Pará. São Paulo, CLADEM/IPÊ, 1996.

RED DE SALUD DE LAS MUJERES LATINOAMERICANAS $Y$ DEL CARIBE. Por el derecho a vivir sin violencia. Acciones y propuestas desde las mujeres. Cuadern Mujer Salud, v.1, 1996.

SAFFIOTI, H.I.B., ALMEIDA, S.S. Violência de gênero: poder e impotência. Rio de Janeiro: Revinter, 1995.

SCHRAIBER, L.B., D'OLIVEIRA, A.F.P.L. Violência, gênero e Saúde: organização serviço e tecnologia de atenção integral à mulher. São Paulo: Faculdade de Medicina USP, DMP; CSE Samuel Pessoa, 1999. (Relatório Final de Pesquisa/CNPq).

SCOTT, J. Gênero: uma categoria útil para a análise histórica. Educ. e Realid. v.20, n.2, 1995.

STARK, E., FLITCRAFT, A. Spouse abuse. In: ROSEMBERG, M. L.; FENLEY, M.A. (Ed.2). Violence in America: A Public Health approach. New York: Oxford University Press, 1991. p.123-57.

STARK, E., FLITCRAFT, A. Women at risk-domestic violence and women's health. London: Sage, 1996.

SUGG, N. K, INUI, T. Primary care physicians' response to domestic violence. JAMA, v.267, n.23, p.3157-60, 1992.

VERARDO, T. Violência. In: D'Oliveira, A.F.L.; LUIZ,O.C.; SORRENTINO, S. (Orgs). Coletânea de textos para o Curso de Capacitação para Atendimento a Mulheres em Situação de Violência. São Paulo: Departamento de Medicina Preventiva, FMUSP, Coletivo Feminista Sexualidade e Saúde, 1995. 
SCHRAIBER, L. B., D'OLIVEIRA, A. F. L. P. Violencia contra mujeres: Interfaces con la Salud, Interface _ Comunicação, Saúde, Educação, v.3 , n.5, 1999.

Este ensayo procurará tratar del tema violencia bajo el recorte de la violencia contra mujeres. Discute la precedencia histórica de la tomada de la violencia contra la mujer como cuestión de Derecho y objeto de la Justicia, trazando paralelos en la emergencia del problema como cuestión de Salud y objetivo de la Salud Pública y de las prácticas médicosanitarias.

PALABRAS-CLAVE: violencia; salud de la mujer; derecho de la mujer; mujer.

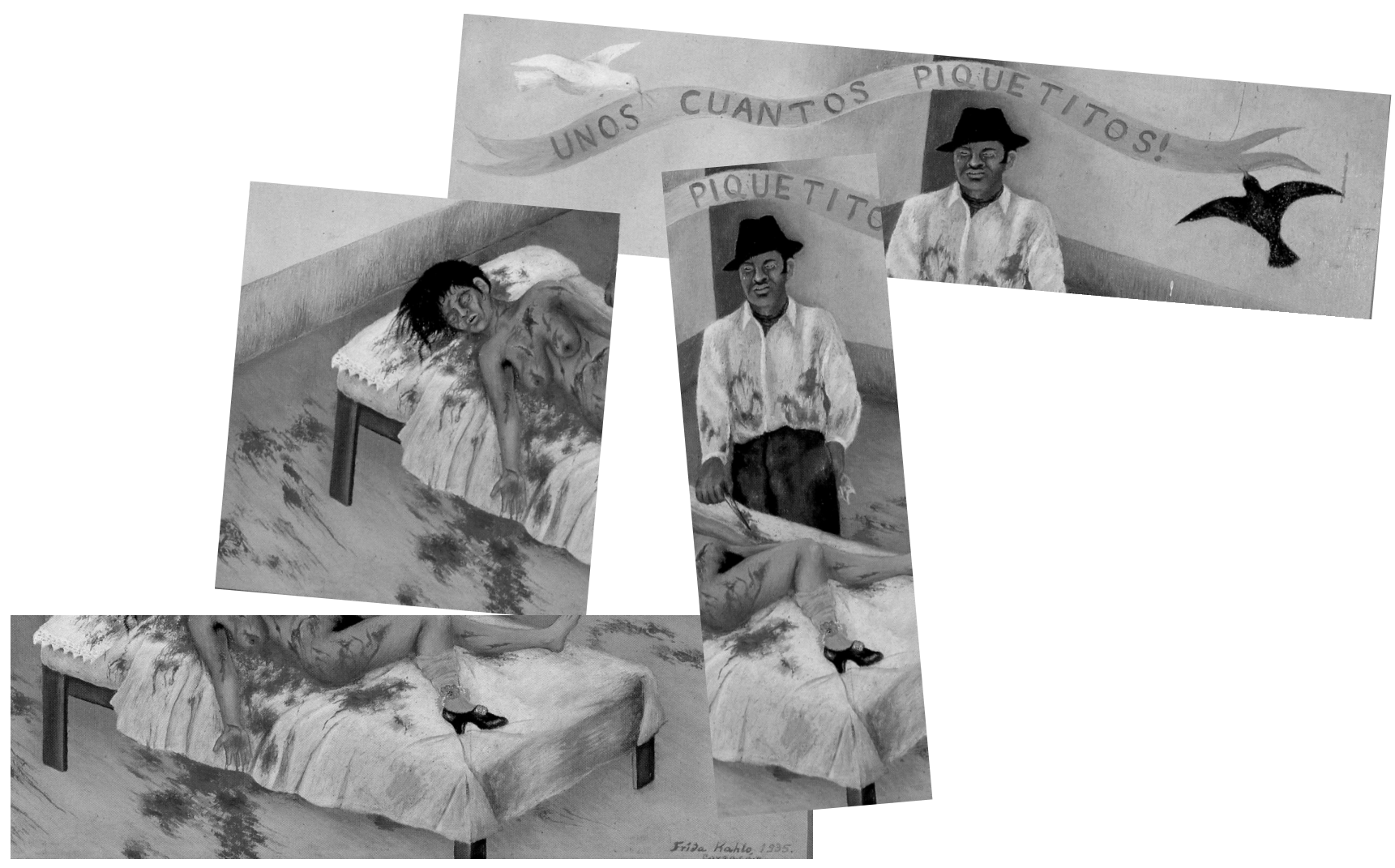

26 Interface - Comunic, Saúde, Educ 5 